\title{
Assessment of the Cases Undergone Peripartum Hysterectomy in a Tertiary Care Hospital in the Last Three Years
}

\author{
Afroz Sayma*, Gulshan Ara \\ Department of Obstetrics \& Gynaecology, Enam Medical College \& Hospital, Savar, Bangladesh \\ Email: *afrozsayma2015@gmail.com
}

How to cite this paper: Sayma, A. and Ara, G. (2018) Assessment of the Cases Undergone Peripartum Hysterectomy in a Tertiary Care Hospital in the Last Three Years. Open Journal of Obstetrics and Gynecology, 8, 1006-1014.

https://doi.org/10.4236/ojog.2018.811101

Received: August 15, 2018

Accepted: September 10, 2018

Published: September 13, 2018

Copyright (c) 2018 by authors and Scientific Research Publishing Inc. This work is licensed under the Creative Commons Attribution-NonCommercial International License (CC BY-NC 4.0).

http://creativecommons.org/licenses/by-nc/4.0/

\begin{abstract}
Background: Emergency peripartum hysterectomy (EPH), although rare in modern obstetrics, remains a life-saving procedure in cases of severe hemorrhage. Objective: To assess the incidence, indications, outcomes \& complications of peripartum hysterecomty performed in a tertiary care hospital \& compare the results with other reports in the literature. Methods: Twenty nine peripartum hysterectomy cases carried out between July 2015 and June 2018 in Enam Medical College \& Hospital, Savar, Dhaka were evaluated retrospectively. Maternal characteristics and characteristics of the present pregnancy and delivery, hysterectomy indications, operative complications, postoperative conditions, and maternal and neonatal outcomes were evaluated. Results: Peripartum hysterectomy incidence was found as 7.26 per 1000 deliveries. The most common indication for hysterectomy was placenta previa with morbidly adherent placenta (17/29) followed by post-partum haemorrhage due to uterine atony (6/29) and ruptured uterus (6/29). There were 6 cases of intraoperative bladder injury. We had 5 maternal deaths, 3 of them were due to irreversible shock \& 2 due to septicaemia. There were 5 cases of neonatal mortality mostly because of prematurity \& asphyxia. All of the placenta previa with placenta accreta cases had at least one previous cesarean section. All 6 ruptured uterus cases had history of previous caesarean section. It was found that blood transfusion was required in all cases. Conclusion: Obstetric hemorrhages are life-threatening clinical conditions \& peripartum hysterectomy is a necessary life-saving procedure. Abnormal placentation is the leading cause of emergency peripartum hysterectomy specially in cases with previous cesarean section history.
\end{abstract}

\section{Keywords}

Peripartum Hysterectomy, Caesarean Section, Placenta Accreta 


\section{Introduction}

Obstetric haemorrhage is one of the leading causes of maternal mortality and morbidity and represents the most challenging complication that an obstetrician will face. Severe postpartum hemorrhage was reported to occur in 6.7/1000 deliveries worldwide [1]. Despite the improvements in conservative medical \& surgical options, peripartum hysterectomy is applied as a life-saving surgical procedure [2].

It was first proposed in 1869 but with no desirable results [3]. However, seven years later (1876), the first cesarean subtotal hysterectomy was carried out successfully, with the result that both the mother and the baby survived [4].

In modern obstetrics, the overall incidence of emergency peripartum hysterectomy is $0.05 \%$, but there are considerable differences in incidence in different parts of the world, depending on modern obstetric services, standards and awareness of antenatal care, and the effectiveness of family planning activities of a given community [5]. The incidence of peripartum hysterectomy in the literature is reported as $0.24,0.77,2.3$, and 5.09 per 1000 deliveries by Sakse et al. [6], Whiteman et al. [7], Bai et al. [8] and Zeteroglu et al. [9], respectively.

The main causes of the uncontrollable hemorrhage necessitating a peripartum hysterectomy have changed since the 1980s [10]. Uterine atony and rupture have been overtaken by abnormal placentation in many studies. This is not only because of improved conservative management of uterine atony and a reduced incidence of uterine rupture due to the extensive use of the lower uterine segment incision in preference to the upper uterine segment incision for cesarean section (CS), but also because of an actual increase in the incidence of the morbidly adherent placenta. Abnormal placentation, which refers to both placenta previa and the morbidly adherent placenta, is thought to be increasing because of the rising rate of CS. Studies have consistently demonstrated that previous CS increases the risk of peripartum hysterectomy and abnormal placentation is associated with a previous uterine scar. It is also established that the risk of peripartum hysterectomy increases with the number of previous CS [11].

Conservative treatment of postpartum hemorrhage includes uterotonics (oxytocin, ergotamine), uterine massage, uterine artery embolization, uterine packing, pelvic vessel ligation, B-Lynch suture, multiple square sutures, and recombinant-activated factor VII [12]. The most severe complication of hemorrhage is maternal death, whose risk is estimated to be approximately 1 in 100,000 deliveries in developed countries. This risk is as high as 1 in 1000 deliveries in developing countries [13].

The objectives of this retrospective study are to examine the incidence, indications, outcomes and complications of peripartum hysterectomy performed in a tertiary teaching hospital, between July 2015 and June 2018 and to compare the results with other reports in the literature. This would help identify avoidable factors, and stress the need to organize health care services so as to improve maternal and fetal outcome. 


\section{Materials and Method}

It is a retrospective descriptive study. Medical \& surgical records of 29 cases of peripartum hysterectomy performed in Enam Medical College \& Hospital, savar, Dhaka during July 2015 to June 2018 were scrutinized. Cases were ascertained via a review of the hospital obstetric records and we ensure that no cases were missed by also checking operation theatre and pathology records. We included all hysterectomies performed after 28 weeks of pregnancy \& within 24 hours of delivery. Maternal age, gravida, parity, previous obstetric history, gestational age were recorded as demographic data. Type of delivery, type \& indication of hysterectomy, complications, postoperative maternal outcome, fetal outcome, blood transfusion, hospital stay were determined as clinical data. Maternal death \& serious urological, neurological, infectious, respiratory, renal \& thromboembolic complications were also checked. Frequencies \& percentages were given as descriptive statistics.

\section{Results}

During 3 years period of study there were 3990 deliveries, among them 29 cases of peripartum hysterectomies identified, the incidence was 7.26 per 1000 deliveries.

According to Table 1 mean patient age was 29 yrs (range 19 - 36 yrs). There was one primiparous woman, rest are multiparous lady. Mean parity \& gravidity were $2.71 \& 3.44$ respectively. Mean gestational age was 34 weeks (range 28 - 39).

Indications for emergency peripartum hysterectomy are shown in Figure 1. The most common indication for peripartum hysterectomy was placenta previa and/or accreta (17/29); followed by PPH due to uterine atony (6/29) and uterine rupture (6/29).

In Table 2 we present obstetric data in relation to the type of delivery. After analysing this chart, we can conclude that the majority of cases (20/29) were cesarean delivery, vaginal delivery in the others (3/29), rest of them were ruptured uterus. In relation to cesarean deliveries, 13/29 were elective cesareans and 5/29 were emergency cesareans. In 2 cases caesarean section was done outside our hospital \& hysterectomy was done due to uncontrolled PPH. Among 28 multiparous patients, 20 patients had previous history of caesarean section (5 patients had 2 caesarean).

The most frequent indications for elective cesareans were placenta previa (11 cases), history of previous 2 cesarean section ( 2 case). Among placenta praevia

Table 1. Demographic data of the patient.

\begin{tabular}{ccc}
\hline & Mean & Min-Max \\
\hline Age & $29 \mathrm{yrs}$ & $19-36 \mathrm{yrs}$ \\
parity & 2.71 & $1-6$ \\
gravida & 3.44 & $1-7$ \\
Gestational age & 34 wks & $28-39$ wks \\
\hline
\end{tabular}


Table 2. Obstetric data.

\begin{tabular}{cl}
\hline Mode of delivery & 20 \\
\hline Caesarean section: & 13 \\
Elective CS & 5 \\
Emergency CS & 2 \\
CS outside & 3 \\
Vaginal delivery & \\
\hline Previous obstetric history & 8 \\
\hline Previous NVD & 20 \\
Previous CS & 6 \\
PPH cases & 2 \\
Caesarean section NVD & 4 \\
Ruptured uterus cases & 6 \\
Previous CS & 6 \\
\hline
\end{tabular}

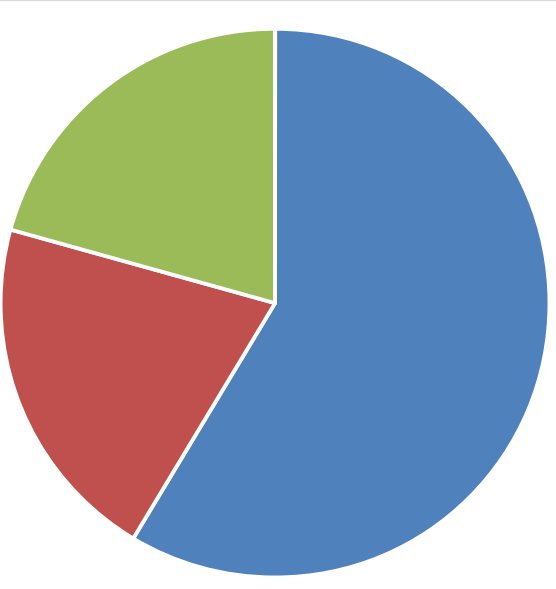

- Placenta praevia with placenta accreta - PPH due to atony $\quad$ - ruptured uterus

Figure 1. Indications of hysterectomy.

cases 9 patient had previous history of caesarean section \& 2 patients had previous normal delivery. 7 cases of placenta previa with history of caesarean section had antenatal diagnosis of placental invasion by ultrasonogram. The emergency cesareans were done because of antepartum haemorrhage, 3 due to placenta praevia \& 2 due to abruptio placentae, 3 of them had history of previous caesarean section.

6 hysterectomies were performed due to intractable obstetric hemorrhage that was unresponsive to conservative management. To avoid hysterectomy, pharmacological agents and conservative surgical procedures were used to control hemorrhage. All patients received oxytocin and ergotamine derivative and misoprostol. Uterine artery ligation \& B-Lynch suture was performed in 3 cases, 
uterine packing was made in 3 other cases. 5 of these women were multiparous andone primiparous. In 4 cases there was history of home delivery. In 2 of thecases (including the primiparous woman) the delivery was performed by cesarean section outside our hospital.

Regarding ruptured uterus, all 6 cases occurred in multiparous women with history of previous caesarean section. One case was in our hospital, she was a case of intrauterine death at 30 weeks and labour was induced. Other 5 cases came from outside with history of home trial in 3 cases \& induction of labour in local clinic in 2 cases. After laparotomy all efforts were made to preserve uterus, but in all cases uterus was irreparable.

Table 3 shows complications of peripartum hysterectomy. There was 6 cases of intraoperative bladder injury due to invasion of bladder by placenta $\&$ one case of ruptured uterus was associated with bladder rupture. All patients received blood transfusions, with the median number of units of blood transfused being 7 (range 2 - 15). We had 4 cases of disseminated intravascular coagulopathy that reversed with prompt management. The mean postoperative hospital stay was 7 (range 5 - 25) days. There were 5 maternal deaths. 2 patients died because of infectious postoperative complications with the development of septic shock, both of them are due to ruptured uterus. 3 patients died due to irreversible shock; 2 atonic cases delivered outside \& one is placenta previa, caesarean section \& peripartum hysterectomy done in our hospital as an emergency procedure. 11 patients required admission in ICU. 9 patients had wound infection \& required secondary suture. Regarding neonatal outcome, the mean birth weight of the 29 infants was 2640 gram (range $1550-3500 \mathrm{gm}$ ). There were 6 cases perinatal mortality (stillbirth \& neonatal death) mostly due to asphyxia \& prematurity.

\section{Discussion}

Emergency peripartum hysterectomy is the last life-saving step in obstetric hemorrhage that cannot be controlled by medical\& conservative surgical methods. Peripartum hysterectomy is performed in persistent obstetric hemorrhages occurring due to lacerations during cesarean section and uterine atony, uterine rupture, placental pathologies and infections.

Table 3. Complications.

\begin{tabular}{cc}
\hline Complications & \\
\hline Bladder injury & 6 \\
DIC & 4 \\
Admission in ICU & 11 \\
Wound infection & 9 \\
Maternal death & 5 \\
Perinatal mortality & 6 \\
\hline
\end{tabular}


The reported incidence of emergency peripartum hysterectomy varies from 0.24 to 5.09 per 1000 deliveries in the literature. In our study, we found peripartum hysterectomy rate 7.26/1000 deliveries, which was high. However, the high rate can be associated with the fact that Enam Medical college hospital is a tertiary referral hospital and cases with high mortality \& morbidity particularly placenta praevia \& ruptured uterus cases are referred to our hospital from other institutions. Zeteroglu et al. reported the incidence of peripartum hysterectomy in a teaching hospital as 5.09/1000 deliveries, which is higher than that of other studies [9].

Cesarean section is the most common surgical procedure preferred by obstetricians. In our study, 20 (69\%) of the cases had at least one previous CS history. In a study performed, it was reported that at least one previous CS history increased peripartum hysterectomy risk 11 times [2]. It was also reported in various studies that placental invasion anomalies such as placenta accreta increase from 18 up to 110 times as the number of previous CS increases [14] [15]. It was also reported that hysterectomy risk was $16 \%$ in placenta previa if previous uterine surgery history is present but the risk decreases $3 \%$ if previous uterine surgery history is not present [10].

There has been a significant change in the indication of peripartum hysterectomy overtime and from one region to another. Traditionally, uterine atony was the most common indication for hysterectomy. Recent studies have indicated that abnormal placentation is replacing uterine atony as the most common indication for peripartum hysterectomy [3]. In 1984, Stanco et al. reported that $43.4 \%$ of their emergency hysterectomies were done because of uterine atony, while $33.9 \%$ were due to placenta previa with accreta. A study from the same institution in 1993 stated that their primary indication was placenta accreta, the problem in $45 \%$ of cases, followed by uterine atony, with $20 \%$ [16]. Baskett reported that the main indications for hysterectomy were abnormal placentation (50\%) and atonic postpartum hemorrhage (32.8\%) [17]. In our study, the most common indication in 29 peripartum hysterectomy cases was placenta accreta (58.6\%), followed by uterine atony (20.6\%) which was consistent with the literature. All of the placenta accreta cases had at least one previous cesarean section along with placenta previa which is also consistent with other studies.

Uterine rupture is commonly associated with vaginal birth after caesarean section, although the absolute risk varies according to previous obstetric history, gestational age, induction of labour \& monitoring facilities [18]. In our study all 6 cases of uterine rupture occurred in multiparous women with history of previous caesarean section. In 3 cases labour was induced for vaginal delivery \& 3 cases patients were in home trial which is consistent with other studies.

Peripartum hysterectomy is associated with high complication rates, mainly due to the need for massive blood transfusions, coagulopathy, and injury of the urinary tract and febrile morbidity [10] [12] [19]. Bladder injury was found in 6 patients and 5 of them had placental invasion \& previous cesarean delivery. 
Thus, urological injuries appear to be related to scarring and secondary adhesion of the vesicouterine space following previous cesarean section and invasion of bladder by placenta. In comparison with Kwee's 15\%, Zeteroglu's 12.5\%, and Lau et al 25\%, our urinary tract injury rate is $20.6 \%$ [9] [10] [20].

Maternal mortality rates are high in peripartum hysterectomy cases.. In the study of Zeteroglu et al. [9] which evaluated deliveries in the Eastern Anatolia Region of Turkey, maternal mortality rate was reported as $16.7 \%$ in peripartum hysterectomy cases. In the retrospective study of Knight [21] analyzing deliveries in the UK, maternal mortality rate was found as $0.6 \%$. The same rate was reported as $23.8 \%$ by the study of Umezurike et al. [22] who analyzed the southeastern region of Nigeria. In our study, maternal mortality was observed in 5 (17.2\%) patients.

In our series, 4 women (14\%) developed disseminated intravascular coagulopathy, lower than the $33 \%$ rate previously reported by Smith and Mousa and Lau et al. [20] [23].

Sherman et al. [24] reported in their study that blood transfusion need in peripartum hysterectomy patients was $100 \%$. Similar to this study, we found in our study that all patients needed blood transfusion and $>98 \%$ of them had over two units of blood.

Our results confirm the previous observations that peripartum hysterectomy is associated with high operative and postoperative complications rates.

The significant limitations of this study are the retrospective design and low number of cases. Further studies are needed on this subject, which have wider series of cases and designed prospectively.

\section{Conclusion}

The patients with previous cesarean section history together with placenta previa are the most vulnerable patient group for peripartum hysterectomy. So, deliveries of such patients should be carried out in tertiary centres by experienced surgeons. The increasing rates of primary caesarean section are likely to contribute to a rise in the incidence of abnormal placentation \& also uterine rupture. Therefore every attempt should be made to reduce primary caesarean section rate by performing it only for valid indication.

\section{Conflicts of Interest}

The authors declare no conflicts of interest.

\section{References}

[1] Waterstone, M., Bewley, S. and Wolfe, C. (2001) Incidence and Predictors of Severe Obstetric Morbidity: Case-Control Study. British Medical Journal, 322, 1089-1093. https://doi.org/10.1136/bmj.322.7294.1089

[2] Selo-Ojeme, D.O., Bhattacharjee, P., Izuwa-Njoku, N.F. and Kadir, R.A. (2005) Emergency Peripartum Hysterectomy in a Tertiary London Hospital. Archives of Gynecology and Obstetrics, 271, 154-159. 
https://doi.org/10.1007/s00404-004-0715-x

[3] Daskalakis, G., Anastasakis, E., Papantoniou, N., Mesogitis, S., Theodora, M. and Antsaklis, A. (2007) Emergency Obstetric Hysterectomy. Acta Obstetricia et Gynecologica Scandinavica, 86, 223-227. https://doi.org/10.1080/00016340601088448

[4] Sturdee, D.W. and Rushton, D.I. (1986) Caesarean and Post-Partum Hysterectomy 1968-1983. British Journal of Obstetrics and Gynaecology, 93, 270-274.

[5] Park, E.H. and Sachs, B.P. (1999) Postpartum Haemorrhage and Other Problems of Third Stage. In: James, D.K., Steer, P.J., Weiner, C.P. and Gonik, B., Eds., High Risk Pregnancy-Management Options, 2nd Edition, W.B. Saunders, Philadelphia, 1231-1246.

[6] Sakse, A., Weber, T., Nickelsen, C. and Secher, N.J. (2007) Peripartum Hysterectomy in Denmark 1995-2004. Acta Obstetriciaet Gynecologica Scandinavica, 86, 1472-1475. https://doi.org/10.1080/00016340701692651

[7] Whiteman, M.K., Kuklina, E. and Hillis, S.D. (2006) Incidenceand Determinants of Peripartum Hysterectomy. Obstetrics and Gynecology, 108, 1486-1492.

https://doi.org/10.1097/01.AOG.0000245445.36116.c6

[8] Bai, S.W., Lee, H.J., Cho, J.S., Park, Y.W., Kim, S.K. and Park, K.H. (2003) Peripartum Hysterectomy and Associated Factors. Journal of Reproductive Medicine for the Obstetrician and Gynecologist, 48, 148-152.

[9] Zeteroglu, S., Ustun, Y., Engin-Ustun, Y., Sahin, G. and Kamaci, M. (2005) Peripartum Hysterectomy in a Teaching Hospital in the Eastern Region of Turkey. European Journal of Obstetrics Gynecology and Reproductive Biology, 120, 57-62. https://doi.org/10.1016/j.ejogrb.2004.08.011

[10] Kwee, A., Bots, M.L., Visser, G.H.A. and Bruinse, H.W. (2006) Emergency Peripartum Hysterectomy: A Prospective Study in the Netherlands. European Journal of Obstetrics Gynecology and Reproductive Biology, 124, 187-192.

https://doi.org/10.1016/j.ejogrb.2005.06.012

[11] Akar, M.E., Yilmaz, E.S., Yuksel, B. and Yilmaz, Z. (2004) Emergency Peripartum Hysterectomy. European Journal of Obstetrics Gynecology and Reproductive Biology, 113, 178-181. https://doi.org/10.1016/j.ejogrb.2003.10.005

[12] Chestnut, D.H., Eden, R.D., Gall, S.A. and Parker, R.T. (1985) Peri-Partum Hysterectomy: A Review of Cesarean and Postpartum Hysterectomy. Obstetrics and Gynecology, 65, 365-370.

[13] Zelop, M., Harlow, B.L., Frigoletto Jr., F.D., Safon, L.E. and Saltzman, D.H. (1993) Emergency Peripartum Hysterectomy. American Journal of Obstetrics and Gynecology, 168, 1443-1448. https://doi.org/10.1016/S0002-9378(11)90779-0

[14] Turner, M.J. (2010) Peripartum Hysterectomy: An Evolving Picture. International Journal of Gynecology \& Obstetrics, 109, 9-11. https://doi.org/10.1016/j.ijgo.2009.12.010

[15] Lone, F., Sultan, A.H., Thakar, R. and Beggs, A.(2010) Risk Factors and Management Patterns for Emergency Obstetric Hysterectomy over 2 Decades. International Journal of Gynecology \& Obstetrics, 109, 12-15. https://doi.org/10.1016/j.ijgo.2009.10.012

[16] Stanco, L.M., Schrimmer, D.B., Paul, R.H. and Mishell, D.R. (1993) Emergency Peripartum Hysterectomy and Associated Risk Factors. American Journal of Obstetrics and Gynecology, 168, 879-883. https://doi.org/10.1016/S0002-9378(12)90838-8

[17] Baskett, T.F. (2003) Emergency Obstetric Hysterectomy. Journal of Obstetrics and Gynaecology, 23, 353-355. https://doi.org/10.1080/0144361031000119466 
[18] Murphy, D.J. (2006) Uterine Rupture. Current Opinion in Obstetrics and Gynecology, 18, 135-140. https://doi.org/10.1097/01.gco.0000192989.45589.57

[19] Zelop, C.M., Harlow, B.L., Frigoletto, F.D., Safon, L.E. and Saltzman, D.H. (1993) Emergency Peripartum Hysterectomy. American Journal of Obstetrics and Gynecology, 168, 1443-1448. https://doi.org/10.1016/S0002-9378(11)90779-0

[20] Lau, W.C., Fung, H.Y.M. and Rogers, M.S. (1997) Ten-Year Experience of Cesarean and Postpartum Hysterectomy in a Teaching Hospital in Hong Kong. European Journal of Obstetrics \& Gynecology and Reproductive Biology, 74, 133-137. https://doi.org/10.1016/S0301-2115(97)00090-0

[21] Knight, M. (2007) Peripartum Hysterectomy in UK: Management and Outcome of the Associated Haemorrhage. BJOG, 114, 1380-1387.

https://doi.org/10.1111/j.1471-0528.2007.01507.x

[22] Umezurike, C.C., Fevi-Waboso, P.A. and Adisa, C.A. (2008) Peripartum Hysterectomy in Aba Southern Nigeria. Australian and New Zealand Journal of Obstetrics and Gynaecology, 48, 580-582.

https://doi.org/10.1111/j.1479-828X.2008.00905.x

[23] Smith, J. and Mousa, H.A. (2007) Peripartum Hysterectomy for Primary Postpartum Haemorrhage: Incidence and Maternal Morbidity. Journal of Obstetrics and Gynaecology, 27, 44-47. https://doi.org/10.1080/01443610601016925

[24] Sherman, S.J., Greenspoon, J.S., Nelson, J.M. and Paul, R.H. (1993) Obstetrics Hemorrhage and Blood Utilization. The Journal of Reproductive Medicine, 38 , 929-934. 